OPEN ACCESS

Edited by:

Wenbin Guo,

Central South University, China

Reviewed by:

Tadashi Watabe,

Osaka University, Japan Jean-Claude Baron, University of Cambridge, United Kingdom

*Correspondence: Masashi Kameyama kame-tky@umin.ac.jp

Specialty section:

This article was submitted to Applied Neuroimaging,

a section of the journal

Frontiers in Neurology

Received: 31 August 2021 Accepted: 17 December 2021

Published: 31 January 2022

Citation:

Kameyama M, Momose T, Ishibashi K and Ishii K (2022) A Novel Proposal for an Index for Regional Cerebral

Perfusion Pressure - A Theoretical Approach Using Fluid Dynamics.

Front. Neurol. 12:765463. doi: 10.3389/fneur.2021.765463

\section{A Novel Proposal for an Index for Regional Cerebral Perfusion Pressure - A Theoretical Approach Using Fluid Dynamics}

\author{
Masashi Kameyama $^{1 *}$, Toshimitsu Momose ${ }^{2}$, Kenji Ishibashi $^{3}$ and Kenji Ishii ${ }^{3}$ \\ ${ }^{1}$ Department of Diagnostic Radiology, Tokyo Metropolitan Geriatric Hospital and Institute of Gerontology, Tokyo, Japan, \\ ${ }^{2}$ Department of Nuclear Medicine, Graduate School of Medicine, The International University of Health and Welfare, Narita, \\ Japan, ${ }^{3}$ Research Team for Neuroimaging, Tokyo Metropolitan Geriatric Hospital and Institute of Gerontology, Tokyo, Japan
}

Cerebral blood flow (CBF) / cerebral blood volume (CBV) ratio derived by [ $\left.{ }^{15} \mathrm{O}\right] \mathrm{H}_{2} \mathrm{O}$ / $\mathrm{CO}_{2}$ and $\mathrm{CO}$ positron emission tomography (PET) examination has been used as an index for cerebral perfusion pressure (CPP). CBF/CBV was demonstrated to be related mean arterial pressure (MAP) in baboons. However, this formula has not been confirmed to be proportionate to CPP. We have developed a new index for CPP using the Poiseuille equation based on a simple model. Our model suggests that $\mathrm{CBF} / \mathrm{CBV}^{2}$ is proportionate to CPP and that it is mathematically a more accurate index than CBF/CBV. This new index needs experimental validation in the future.

Keywords: positron emission tomography (PET), cerebral blood flow (CBF), cerebral blood volume (CBV), cerebral perfusion pressure (CPP), fluid mechanics

\section{INTRODUCTION}

Cerebral perfusion pressure (CPP) is the driving force for cerebral blood flow $(\mathrm{CBF})$ and, therefore, is an important factor for evaluation of a patient's cerebral hemodynamic state. However, a non-invasive method for measuring local $\mathrm{CPP}$ directly has yet to be developed.

As the $\mathrm{CBF} /$ cerebral blood volume (CBV) ratio derived by $\left[{ }^{15} \mathrm{O}\right] \mathrm{H}_{2} \mathrm{O} / \mathrm{CO}_{2}$ and $\mathrm{CO}$ positron emission tomography (PET) examination reflected artery patency, $\mathrm{CBF} / \mathrm{CBV}$ was proposed as an index for hemodynamic reserve (1). $\mathrm{CBF} / \mathrm{CBV}$ was further found to be related to oxygen extraction fraction (2) and mean arterial pressure (MAP) in baboons (3). Based on these findings, $\mathrm{CBF} / \mathrm{CBV}$ came to be used as an index for CPP $(4,5)$. When CPP decreases, CBV increases and CBF decreases, therefore, $\mathrm{CBF} / \mathrm{CBV}$ certainly shows some relation to $\mathrm{CPP}$. $\mathrm{As} \mathrm{CBF} / \mathrm{CBV}$ is the reciprocal number of mean transit time (6), it is proportionate to the mean velocity of blood. Certainly the fluid velocity falls according to the decrease in pressure (1-3).

Whilst $\mathrm{CBF} / \mathrm{CBV}$ rises as $\mathrm{CPP}$ rises and vice versa, there is no evidence of ratio scale (i.e., there is no evidence that changes in $\mathrm{CBF} / \mathrm{CBV}$ is proportional to changes in $\mathrm{CPP}$ ). In this study, $\mathrm{CPP}$ was theoretically derived from $\mathrm{CBF}$ and $\mathrm{CBV}$ using fluid dynamics.

\section{THEORY}

Assume there is one small cerebral region which contains one vessel. The vessel is the sole blood supply for the entire region (Figure 1). 


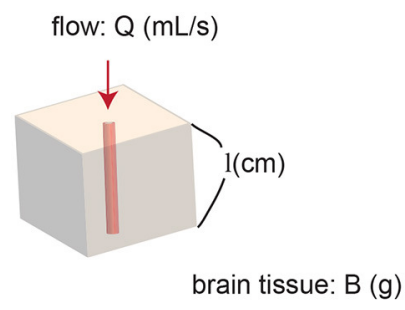

FIGURE 1 | Model of a region of brain. The region contains one vessel. The vessel supplies blood flow to the entire region.

The Poiseuille equation, which can be derived from the Navier-Stokes equations (7) describes incompressible fluid in lamina flow through a long pipe:

$$
\Delta p=\frac{8 \mu l Q}{\pi r^{4}}
$$

where $\Delta p$ denotes pressure difference between the two ends [i.e., local CPP $(\mathrm{Pa})], \mu$ is dynamic viscosity $(\mathrm{Pa} \cdot \mathrm{min}), l$ is length of the vessel $(\mathrm{cm}), Q$ is volumetric flow rate $(\mathrm{mL} / \mathrm{min})$, and $r$ is radius of the vessel $(\mathrm{cm})$.

$\mathrm{CBF}$ and $\mathrm{CBV}$ can be calculated as follows:

$$
\begin{aligned}
& \mathrm{CBF}=Q / B \quad(\mathrm{~mL} / \mathrm{g} / \mathrm{min}) \\
& \mathrm{CBV}=\pi r^{2} l / B \quad(\mathrm{~mL} / \mathrm{g})
\end{aligned}
$$

where $\mathrm{B}$ denotes local brain tissue weight including the one vessel ( $\mathrm{g})$.

Therefore,

$$
\mathrm{CPP}=\frac{8 \pi \mu l^{3}}{B} \frac{\mathrm{CBF}}{\mathrm{CBV}^{2}}
$$

As $\mu$ is constant and the volume of the brain region perfused by the single vessel is also approximately constant, CPP is proportional to $\mathrm{CBF} / \mathrm{CBV}^{2}$.

Here, we would like to calculate cerebrovascular resistance (CVR).

$$
\mathrm{CBF}=\mathrm{CPP} / \mathrm{CVR}
$$

The Equation (1) can be arranged as follows using Equation (2):

$$
\mathrm{CPP}=\frac{8 \mu l B}{\pi r^{4}} \frac{Q}{B}=\frac{8 \mu l B}{\pi r^{4}} \mathrm{CBF}
$$

Therefore,

$$
\mathrm{CVR}=\frac{\mathrm{CPP}}{\mathrm{CBF}}=\frac{8 \mu l B}{\pi} \frac{1}{r^{4}}
$$

Hence, CVR is proportionate to $1 / r^{4}$.

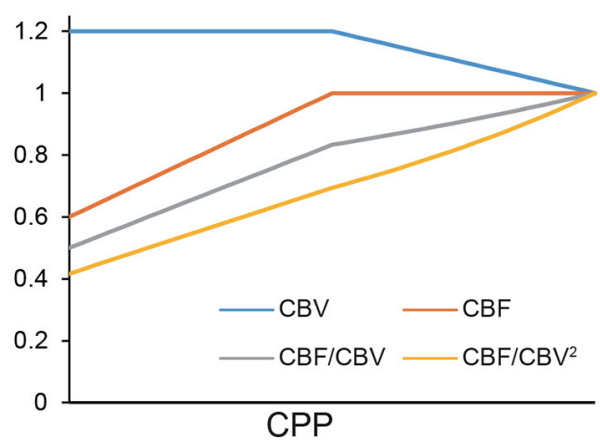

FIGURE 2 | A simulation of $\mathrm{CBF} / \mathrm{CBV}$ and $\mathrm{CBF} / \mathrm{CBV}^{2}$.

\section{METHODS}

\section{Simulation}

A simulation was executed to demonstrate how $\mathrm{CBF} / \mathrm{CBV}$ and $\mathrm{CBF} / \mathrm{CBV}^{2}$ behave using a standard spreadsheet software, Excel (Microsoft Corporation, Redmond, WA, USA). It was run under the condition that the rate reduction of CBF per CPP after the auto-regulation limit [Powers' Stage II (8)] was twice the CBV elevation per CPP before the limit was reached (Stage I). The unit was a relative scale.

\section{Reanalysis of Mean Arterial Pressure and $\mathrm{CBF} / \mathrm{CBV}^{2}$}

$\mathrm{CBF} / \mathrm{CBV}$ and $\mathrm{CBF} / \mathrm{CBV}^{2}$ were calculated from $\mathrm{CBF}$ $(\mathrm{mL} / 100 \mathrm{~mL} / \mathrm{min})$ and $\mathrm{CBV}(\mathrm{mL} / 100 \mathrm{~mL})$ of the published study with baboons (3). The calculated values were plotted against MAP. Pearson's correlation coefficient and the linearity of the regression were assessed.

\section{Application to ${ }^{15}$ O PET Study}

One normal participant and one patient with Moyamoya disease were analyzed. The procedure of ${ }^{15} \mathrm{O}$ PET study was documented in Hara et al. (9). Both participants were scanned with Discovery 710 PET/CT system (GE Healthcare, Milwaukee, WI, USA).

\section{RESULTS}

\section{Simulation}

$\mathrm{CBF} / \mathrm{CBV}^{2}$ showed better linearity than $\mathrm{CBF} / \mathrm{CBV}$ (Figure 2).

\section{Reanalysis of MAP and CBF/CBV ${ }^{2}$}

$\mathrm{CBF} / \mathrm{CBV}$ and $\mathrm{CBF} / \mathrm{CBV}^{2}$ were plotted against MAP (Figure 3). Both $\mathrm{CBF} / \mathrm{CBV}$ and $\mathrm{CBF} / \mathrm{CBV}^{2}$ showed significant correlation with MAP $\left(\mathrm{CBF} / \mathrm{CBV} r=0.8229, p=2.398 \times 10^{-8}\right.$; $\left.\mathrm{CBF} / \mathrm{CBV}^{2} r=0.6833, p=3.157 \times 10^{-5}\right)$. Regression lines were $\mathrm{CBF} / \mathrm{CBV}=0.0744 \mathrm{MAP}+3.259$ and $\mathrm{CBF} / \mathrm{CBV}^{2}=0.0304$ $\mathrm{MAP}+0.6919 . \mathrm{CBF} / \mathrm{CBV}$ showed better correlation coefficient, however, it showed larger intercept.

\section{Application to ${ }^{15}$ O PET Study}

$\mathrm{CBF}, \mathrm{CBV}, \mathrm{CBF} / \mathrm{CBV}, \mathrm{CBF} / \mathrm{CBV}^{2}$, OEF were calculated for a normal participant and a patient with Moyamoya disease 

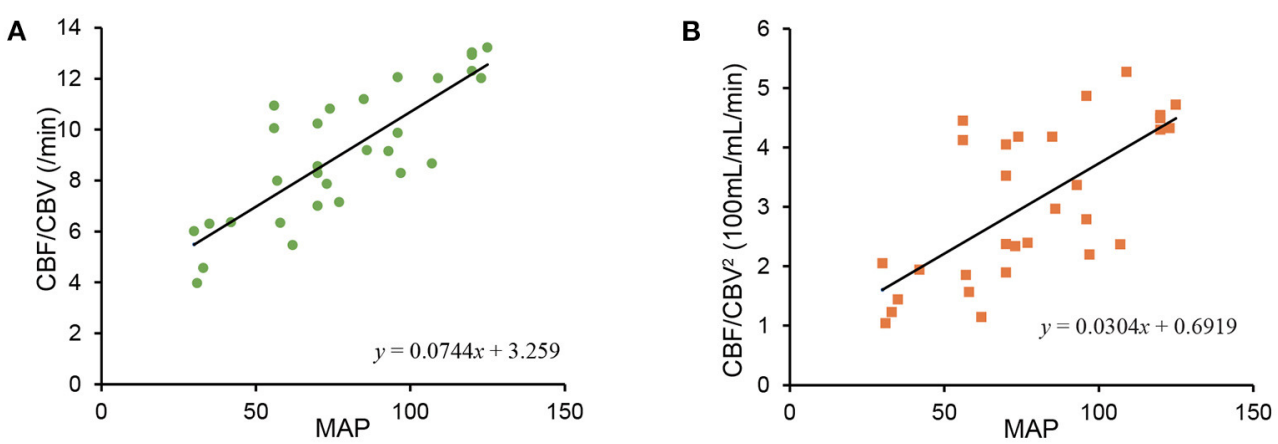

FIGURE 3 | Relationship between mean arterial blood pressure (MAP) and CBF/CBV (A), between MAP and CBF/CBV² (B)

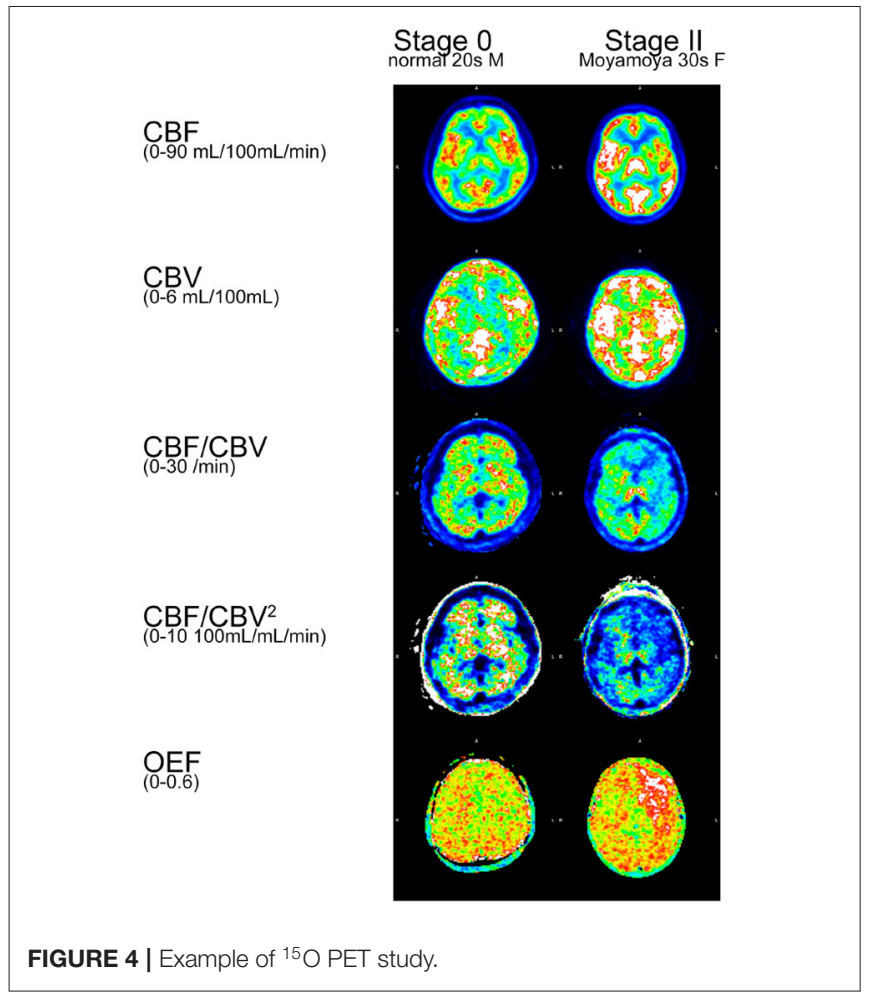

(Figure 4). $\mathrm{CBF} / \mathrm{CBV}^{2}$ showed pronounced decrease in entire brain of patient with Moyamoya disease.

\section{DISCUSSION}

We have demonstrated theoretically that $\mathrm{CBF} / \mathrm{CBV}^{2}$ is an appropriate indicator for $\mathrm{CPP}$. $\mathrm{CBF} / \mathrm{CBV}$ is the reciprocal number of mean transit time (6). Therefore, it is proportionate to the mean velocity of blood, and certainly relates to CPP. However, our theoretical approach implies that $\mathrm{CBF} / \mathrm{CBV}^{2}$ would be a better approximation for $\mathrm{CPP}$ than $\mathrm{CBF} / \mathrm{CBV}$.

The linearity shown in Figure $\mathbf{2}$ was determined in part by our assumption of $\mathrm{CBF}$ reduction being twice that of $\mathrm{CBV}$ elevation.
However, this is a reasonable assumption considering the fluid dynamics equations above. Within auto-regulation limit (Stage I), Equations $(1,3)$ tells that $\mathrm{CBV}$ is proportionate to $\mathrm{CPP}^{-0.5}$, therefore, $\triangle \mathrm{CBV} \simeq k\left(-\frac{1}{2}\right) \triangle \mathrm{CPP}$ ( $k$ : constant). In Stage II, Equations $(1,2)$ tells that $\mathrm{CBF}$ is proportionate to CPP.

Figure 2 showed small difference between $\mathrm{CBF} / \mathrm{CBV}$ and $\mathrm{CBF} / \mathrm{CBV}^{2}$. This simulation confirmed $\mathrm{CBF} / \mathrm{CBV}$ as an index for $\mathrm{CPP}$ although it is not a ratio scale.

Reanalysis of $\mathrm{MAP}$ and $\mathrm{CBF} / \mathrm{CBV}, \mathrm{CBF} / \mathrm{CBV}^{2}$ (Figure 3) showed less stability of $\mathrm{CBF} / \mathrm{CBV}^{2}$. The instability may be attributable to spill over from $\left[{ }^{15} \mathrm{O}\right] \mathrm{CO}$ in venous and physiologically small proportion of CBV (about $4 \%$ of brain tissue). As $\mathrm{CBV}$ being small is difficult to measure with accuracy, $\mathrm{CBF} / \mathrm{CBV}^{2}$ may not be reliable comparing to $\mathrm{CBF} / \mathrm{CBV}$ in a physical world. However, regression line of $\mathrm{CBF} / \mathrm{CBV}^{2}$ passed near origin, which would demonstrate potential superiority.

Calculated $\mathrm{CBF} / \mathrm{CBV}^{2}$ images (Figure 4) showed pronounced decrease in entire brain of patient with Moyamoya disease, comparing with $\mathrm{CBF} / \mathrm{CBV}$ images. Considering serious prognosis of Moyamoya disease, $\mathrm{CBF} / \mathrm{CBV}^{2}$ images would reflect the status of the disease. Furthermore, the figure showed that clearly elevated OEF in the area of low $\mathrm{CBF} / \mathrm{CBV}^{2}$, which is consistent with the well established notion that high OEF is a very sensitive index of lost autoregulation (10).

The Poiseuille equation is applicable under the conditions of laminar flow in a long tube. Thus, our conclusions may not be applicable in situations of turbulent flow. However, the effect of turbulent flow are likely limited as Reynolds number $\left(\frac{2 r \rho v}{\mu}\right) \quad(v$ : velocity of fluid, $\rho$ : the density of the fluid) of small vessel is small (capillary: 0.0007-0.003, arteriole: 210-570, Reynolds number smaller than 2300 indicates laminar flow).

This new index needs experimental validation in the future.

\section{DATA AVAILABILITY STATEMENT}

The original contributions presented in the study are included in the article/supplementary 
material, further inquiries can be directed to the corresponding author/s.

\section{AUTHOR CONTRIBUTIONS}

MK contributed to the conceptualization, creation of theory, and initial draft manuscript preparation. TM advised the project. KIshib and KIshii contributed the calculation of ${ }^{15} \mathrm{O}$ PET studies. All the authors

\section{REFERENCES}

1. Gibbs JM, Leenders KL, Wise RJS, Jones T. Evaluation of cerebral perfusion reserve in patients with carotid-artery occlusion. Lancet. (1984) 323:310-4. doi: 10.1016/s0140-6736(84)90361-1

2. Sette G, Baron JC, Mazoyer B, Levasseur M, Pappata S, Crouzel C. Local brain haemodynamics and oxygen metabolism in cerebrovascular disease: positron emission tomography. Brain. (1989) 112:931-51. doi: 10.1093/brain/112.4.931

3. Schumann P, Touzani O, Young AR, Morello R, Baron JC, MacKenzie ET. Evaluation of the ratio of cerebral blood flow to cerebral blood volume as an index of local cerebral perfusion pressure. Brain. (1998) 121:1369-79. doi: 10.1093/brain/121.7.1369

4. Okazawa H, Yamauchi H, Toyoda H, Sugimoto K, Fujibayashi Y, Yonekura Y. Relationship between vasodilatation and cerebral blood flow increase in impaired hemodynamics: a PET study with the acetazolamide test in cerebrovascular disease. J Nucl Med. (2003) 44:1875-83.

5. Watabe T, Shimosegawa E, Kato H, Isohashi K, Ishibashi M, Hatazawa J. $\mathrm{CBF} / \mathrm{CBV}$ maps in normal volunteers studied with ${ }^{15} \mathrm{O}$ PET: a possible index of cerebral perfusion pressure. Neurosci Bull. (2014) 30:857-62. doi: 10.1007/s12264-013-1458-0

6. Meier P, Zierler KL. On the theory of the indicator-dilution method for measurement of blood flow and volume. $J$ Appl Physiol. (1954) 6:731-44. doi: 10.1152/jappl.1954.6. 12.731

7. Stokes GG. On the theories of the internal friction of fluids in motion, and of the equilibrium and motion of elastic solids. Trans Cambridge Philos Soc. (1845) 8:287-319.

8. Derdeyn CP, Videen TO, Yundt KD, Fritsch SM, Carpenter DA, Grubb RL, et al. Variability of cerebral blood volume and oxygen extraction: stages of discussed the project and have read and approved the final manuscript.

\section{ACKNOWLEDGMENTS}

The authors would like to thank Prof. Pascale SchumannBard for providing ${ }^{15} \mathrm{O}$ PET data of baboons (3), and Dr. Natalie Okawa for English language editing of this manuscript.

cerebral haemodynamic impairment revisited. Brain. (2002) 125:595-607. doi: 10.1093/brain/awf047

9. Hara S, Kudo T, Hayashi S, Inaji M, Tanaka Y, Maehara T, et al. Improvement in cognitive decline after indirect bypass surgery in adult moyamoya disease: implication of ${ }^{15} \mathrm{O}$-gas positron emission tomography. Ann Nucl Med. (2020) 34:467-75. doi: 10.1007/s12149-020-01473-8

10. Baron JC, Bousser MG, Rey A, Guillard A, Comar D, Castaigne P. Reversal of focal "misery-perfusion syndrome" by extra-intracranial arterial bypass in hemodynamic cerebral ischemia. A case study with ${ }^{15} \mathrm{O}$ positron emission tomography. Stroke. (1981) 12:454-9. doi: 10.1161/01.str.12.4.454

Conflict of Interest: The authors declare that the research was conducted in the absence of any commercial or financial relationships that could be construed as a potential conflict of interest.

Publisher's Note: All claims expressed in this article are solely those of the authors and do not necessarily represent those of their affiliated organizations, or those of the publisher, the editors and the reviewers. Any product that may be evaluated in this article, or claim that may be made by its manufacturer, is not guaranteed or endorsed by the publisher.

Copyright (C) 2022 Kameyama, Momose, Ishibashi and Ishii. This is an open-access article distributed under the terms of the Creative Commons Attribution License (CC $B Y)$. The use, distribution or reproduction in other forums is permitted, provided the original author(s) and the copyright owner(s) are credited and that the original publication in this journal is cited, in accordance with accepted academic practice. No use, distribution or reproduction is permitted which does not comply with these terms. 